\title{
Shrubs facilitate recruitment of Caragana stenophylla Pojark: microhabitat amelioration and protection against herbivory
}

\author{
Li-Na Xie ${ }^{1,2} \cdot$ Hong-Yu Guo ${ }^{1} \cdot$ Zhe Liu $^{1} \cdot$ Christopher A. Gabler ${ }^{3} \cdot$ Wei-Zhong Chen ${ }^{1}$. \\ Song $\mathrm{Gu}^{2} \cdot$ Cheng-Cang $\mathrm{Ma}^{1}$
}

Received: 9 February 2017 / Accepted: 17 October 2017 / Published online: 25 October 2017

(C) INRA and Springer-Verlag France SAS 2017

\begin{abstract}
- Key message Mature Caragana stenophylla shrubs facilitated intraspecific sapling establishment by two mechanisms: microhabitat amelioration and protection against herbivory. Facilitation was mediated by climate, grazing, and sapling age.

- Context Pre-existing shrubs could facilitate sapling establishment of woody plants; however, how these facilitation vary across abiotic and biotic stress gradients and the underlying mechanisms remain unclear.

- Aims The aim of this study is understanding the facilitation of shrub on sapling establishment and how the two underlying mechanisms, microhabitat amelioration and protection against herbivory, vary across climatic aridity gradients, grazing gradients, and sapling age.

- Methods We conducted field sowing experiments to examine the facilitation of mature Caragana stenophylla Pojark on intraspecific sapling establishment.
\end{abstract}

Handling editor: Laurent Bergès

Electronic supplementary material The online version of this article (https://doi.org/10.1007/s13595-017-0668-4) contains supplementary material, which is available to authorized users.

Cheng-Cang Ma

machengcang@163.com

Li-Na Xie

xielina1989@163.com

Hong-Yu Guo

hongyuguo88@163.com

Zhe Liu

326578633@qq.com

Christopher A. Gabler

christopher.gabler@utrgv.edu
- Results Facilitation of $C$. stenophylla on sapling survival increased as drought stress, grazing intensity, and sapling age increased. Microhabitat amelioration increased as drought stress and sapling age increased. Similarly, protection against herbivory increased as drought stress, grazing intensity, and sapling age increased. Relative importance of microhabitat amelioration increased as drought stress increased, and relative importance of protection against herbivory increased as grazing intensity and sapling age increased.

- Conclusion Facilitation of shrub on sapling establishment involves both microhabitat amelioration and protection against herbivory. Facilitation, the two mechanisms, and relative importance between the two mechanisms would all be affected by climatic aridity, grazing intensity, and sapling age. Shrub establishment has a positive feedback effect.

Wei-Zhong Chen

15922042583@126.com

Song Gu

songgu@nankai.edu.cn

Tianjin Key Laboratory of Animal and Plant Resistance, College of Life Sciences, Tianjin Normal University, Tianjin, China

2 College of Life Sciences, Nankai University, Tianjin, China

3 School of Earth, Environmental, and Marine Sciences and Department of Biology, University of Texas Rio Grande Valley, Brownsville, TX, USA 
Keywords Climatic aridity gradient · Grazing · Sapling establishment · Nurse plants · Plant facilitation efficiency . Stress gradient hypothesis

\section{Introduction}

Biotic interactions could change along stress gradients (stress gradient hypothesis) (Bertness and Callaway 1994; Brooker et al. 2008; Maestre et al. 2009). Many studies showed that plant interactions would shift from competition to facilitation as environmental stress increased (Tielbörger and Kadmon 2000; Pugnaire and Luque 2001; Callaway et al. 2002), and facilitation became more common in more stress versus more benign environmental conditions (Choler et al. 2001; GómezAparicio 2009; Maestre et al. 2009; Petrou and Milios 2012). In contrast, some other studies showed that plant interactions might not respond to stress changes (Maestre et al. 2005; Cavieres et al. 2006; He et al. 2013), and the relationship between biotic interaction and environmental stress gradient often exhibits variation among different species (Holmgren et al. 2012).

Sapling establishment is the critical stage of woody plant population growth. Many studies have shown that shrub presence can facilitate sapling establishment in harsh environments (Holl 2002; Castro et al. 2004; Aerts et al. 2006). Alternatively, other studies have found a lack of evidences to support the hypothesis that shrubs facilitate sapling recruitment and survival (Williams et al. 2006; López et al. 2007). However, there have been few studies on facilitative effects of shrubs on sapling establishment across gradients of environmental stress (Hastwell and Facelli 2003), grazing intensity (Smit et al. 2007), and growth stage. Studies have shown that facilitation of trees on shrub sapling survival was high under severe physical environments (Hastwell and Facelli 2003); conversely, the facilitation of nurse shrub on sapling survival reduced as grazing pressure increased (Smit et al. 2007).

Some previous studies suggest that the facilitative effects of shrubs arise, mechanistically, because shrubs are able to ameliorate stressful abiotic conditions and thereby create microhabitats with environmental conditions that are relatively favorable for the survival and/or growth of seedlings/saplings (Gómez-Aparicio et al. 2005a, b, 2008; Smit et al. 2008; Gómez-Aparicio 2009; Legras et al. 2010; Otto et al. 2010). For example, it has been shown that, within their vicinity, shrubs can increase shade (Smit et al. 2008; Jankju 2013), reduce wind velocity (Martínez 2003), increase soil nutrient enrichment (e.g., higher extractable $\mathrm{P}$ and $\mathrm{K}$, organic matter, and total nitrogen), increase cation exchange capacity, increase soil moisture (Chambers 2001), reduce soil temperature (Martínez 2003; Jankju 2013; Caldeira et al. 2014), restrict soil water evaporation and seedling transpiration (Aerts et al. 2007; Gutiérrez et al. 2007), and increase sand accretion
(Martínez 2003). Other studies suggest that shrubs facilitate sapling establishment by protecting saplings from herbivory (Grau et al. 2010; Harmer et al. 2010; Maher et al. 2010; Torres and Renison 2015; Tálamo et al. 2015a, b). Thus, in general, there would be two important mechanisms by which shrubs may facilitate sapling establishment, specifically microhabitat amelioration or protection against herbivory (Bertness and Callaway 1994). However, very few studies have shown that shrubs can facilitate the sapling survival through both mechanisms, i.e., by both ameliorating harsh abiotic conditions and protecting saplings against grazing (Boulant et al. 2008, 2009). Thus, the relative importance of these two mechanisms across gradients of environmental stress and herbivore pressure remains unclear.

The Inner Mongolia Plateau, located in the northern China, spans an extensive area $\left(\sim 1183 \times 10^{3} \mathrm{~km}^{2}\right)$, ranging from $97^{\circ}$ $12^{\prime} \mathrm{E}$ to $126^{\circ} 04^{\prime} \mathrm{E}$ in longitude (a distance of $2500 \mathrm{~km}$ ) and $37^{\circ} 24^{\prime} \mathrm{N}$ to $53^{\circ} 23^{\prime} \mathrm{N}$ in latitude (a distance of $1700 \mathrm{~km}$ ). There is a strong gradient of increasing climatic aridity (across humid, sub-humid, semi-arid, arid, very arid, intensively arid, and extremely arid zones) from the northeast to the southwest. Overgrazing has become a common phenomenon in the region since the 1970s and is a main cause of ecosystem degradation on the Inner Mongolia Plateau. Given its strong climatic aridity gradient and potentially high grazing disturbance, the Inner Mongolia Plateau provides an ideal system for studying the mechanisms by which shrubs may facilitate sapling establishment and thereby evaluating the relative importance of microhabitat amelioration and protection against herbivory in shaping these plant-plant interactions along stress gradients.

Caragana is the main genus of shrub species on the Inner Mongolia Plateau. Caragana stenophylla Pojark is the species of Caragana genus that has the largest distribution range across the Inner Mongolia Plateau. It is predominately distributed from the semi-arid zone to the intensively arid zone (Ma et al. 2013; Xie et al. 2015). It has not only economic value as fodder, green manure, and honey resource but also environmental protection value for wind erosion, sand fixation, and water and soil conservation and plays increasingly important roles in mediating ecosystem functions and services. Morphologically, C. stenophylla is a spinose shrub species with relative compact, cushion-like canopies. As a result, C. stenophylla shrubs can improve conditions within the microenvironment under their canopies (Guan et al. 2016; Liu et al. 2016) and also resist disturbances such as trampling and feeding by ungulate animals.

We hypothesized that the facilitative effects of pre-existing C. stenophylla shrubs on C. stenophylla seed germination and sapling survival would increase as drought stress, grazing intensity, and sapling growth time increase. We also hypothesized that the facilitative effects due to microhabitat amelioration or/and protection against herbivory as well as the relative 
importance of microhabitat amelioration versus protection against herbivory would all be affected by climatic condition, grazing intensity, and sapling growth time.

To test our hypotheses, we examined the effects of shrub presence on both seed germination and saplings survival of a regionally important woody species, C. stenophylla, across four climatic aridity zones (semi-arid, arid, very arid, and intensively arid zones), three grazing intensities (fenced, mild grazing, and severe grazing), and two growth stages (6-month seedling and 18-month sapling) using manipulative sowing experiments on the Inner Mongolia Plateau. Our study provides important insight into key mechanisms by which preexisting shrubs can facilitate the establishment of shrubs.

\section{Materials and methods}

\subsection{Experimental design}

We conducted the field work at four study sites: (1) Xilinhaote in the semi-arid zone, (2) Siziwang in the arid zone, (3) Etuoke in the very arid zone, and (4) Alashanzuo in the intensively arid zone of the Inner Mongolia Plateau. The geographical location and environmental data of these study sites are shown in Table 1 and Supporting data 1.

At each study site, we selected three adjacent plots, arrayed from the east to the west, with different managements: fenced (F), mildly grazed (M), and severely grazed (S) (Supporting data 2). Each plot was more than 500 ha. Within each plot, we demarcated three sub-plots ( $\sim 3$ ha each sub-plot) arrayed from the north to the south (i.e., sub-plot 1, sub-plot 2, and sub-plot 3 ) with distances of $\sim 800 \mathrm{~m}$ between sub-plots. We took the three sub-plot 1 areas (sub-plot 1-F, sub-plot 1-M and sub-plot $1-\mathrm{S}$ ) as replication group 1, the three sub-plot 2 areas (sub-plot 2-F, sub-plot 2-M and sub-plot 2-S) as replication group 2, and the three sub-plot 3 areas (sub-plot 3-F, sub-plot 3-M and sub-plot 3-S) as replication group 3, respectively (Supporting data 2). The topographic and bedrock characteristics were similar among the replication groups.

Vegetation coverage decreases gradually as climatic drought stress increases from the semi-arid zone to the intensively arid zone; thus, the grazing intensity was set according to the local vegetation conditions for logistical reasons and to keep the grassland vegetation utilization roughly equivalent. In other words, even though the stocking densities varied across sites within a given grazing treatment, the expected grazing pressure exerted on vegetation within a given grazing treatment is approximately equal across sites. Grassland vegetation utilization rate was $30-35 \%$ under the mildly grazed management and 60-70\% under the severely grazed management. The grazing intensities for mildly grazed and severely grazed managements at each study site were as

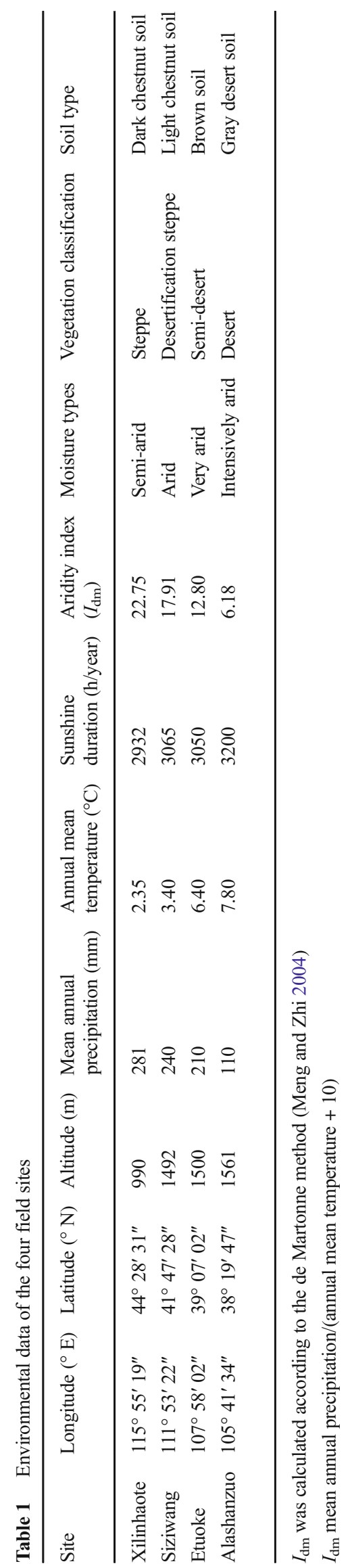


following: for mildly grazed management, 1.2 sheep per hectare in Xilinhaote (in the semi-arid zone), 1.0 sheep per hectare in Siziwang (in the arid zone), 0.8 sheep per hectare in Etuoke (in the very arid zone), and 0.4 sheep per hectare in Alashanzuo (in the intensively arid zone) and for severely grazed management, 2.8 sheep per hectare in Xilinhaote, 1.9 sheep per hectare in Siziwang, 1.5 sheep per hectare in Etuoke, and 0.8 sheep per hectare in Alashanzuo.

During June-July of 2012, we collected and air-dried healthy $C$. stenophylla seeds from each of the four sites. We put the seed outdoor in the winter of 2012 and measured germination rates in March of 2013. Overall germination rates of C. stenophylla seeds were 91-93\%. Neither the germination rate nor the germination index of seeds from different climatic aridity zones was significantly different.

We conducted the field experiments in 2013 and 2014. Compared with historical averages, both precipitation and spring temperature were relatively lower in 2013; while precipitation was relatively higher in 2014 . At the beginning of the 2013 growing season, we sowed seeds within plots that had been collected from the same site in the previous year. The timing of the growing season varies among our study sites, so we sowed the seeds at different sites on different dates according to the local growing season. Sowing dates were April 20 at the Alashanzuo site, April 26 at the Etuoke site, May 1 at the Siziwang site, and May 8 at the Xilinhaote site.

In each sub-plot, we selected 12 C. stenophylla shrub clusters using the line transect method. Canopy area of the shrub clusters was $0.8-1.5 \mathrm{~m}^{2}$, and height of the shrub clusters was 30-40 cm. For each C. stenophylla shrub cluster, we sowed

100 seeds of $C$. stenophylla inside the shrub canopy (in a 1$\mathrm{m} \times 1-\mathrm{m}$ area around the centre of the shrub; if canopy area $<1 \mathrm{~m}^{2}$, we ensured that all $C$. stenophylla seeds sowed were inside the canopy). We also sowed 100 seeds in open spaces outside the shrub canopy (within a $1-\mathrm{m} \times 1-\mathrm{m}$ area that was $2 \mathrm{~m}$ away from the edge of the shrub canopy). Our previous study (Xie et al. 2015) has investigated the seed densities of C. stenophylla in soils inside (semi-arid zone, 4 seeds $/ \mathrm{m}^{2}$; arid zone, 3 seeds $/ \mathrm{m}^{2}$; very arid zone, 2 seeds $/ \mathrm{m}^{2}$; intensively arid zone, $1 \mathrm{seed} / \mathrm{m}^{2}$ ) and outside shrub canopies (semi-arid zone, 3 seeds $/ \mathrm{m}^{2}$; arid zone, $1 \mathrm{seed} / \mathrm{m}^{2}$; very arid zone, $1 \mathrm{seed} / \mathrm{m}^{2}$; intensively arid zone, $0 \mathrm{seed} / \mathrm{m}^{2}$ ). Thus, we deducted the number of pre-existing seeds in soil when sowing seeds. Six months after sowing these seeds (at the end of the growing season in 2013) and 18 months after sowing (at the end of the growing season in 2014), we recorded the number of surviving seedlings (6 months old) or saplings (18 months old), respectively, both within the seed addition shrub canopies and in the seed addition areas in open space. For each subplot, we calculated the number of surviving seedlings or saplings in the experimental shrub canopies and open areas (DOI: https://doi.org/10.5061/dryad.30tg8).

\subsection{Data analysis}

We evaluated the facilitative effect of pre-existing shrubs on seedlings or saplings using plant facilitation efficiency (thereafter abbreviated as PFE), which could also be applied for other plant species (including shrubs, trees, tussock, etc.) We calculated the PFE of C. stenophylla for each sub-plot according to the formula:

$\mathrm{PFE}=\left(\begin{array}{c}\text { number of survival seedlings or saplings inside } \\ \text { shrub canopies-number of survival seedlings or saplings in open spaces }\end{array}\right) / \begin{gathered}\text { /number of survival seedlings } \\ \text { or saplings in open spaces }\end{gathered}$

Positive PFE values indicated that shrubs had facilitative effects on seedlings/saplings. PFE values of zero (or indistinguishable from zero) indicated that shrubs had no effect on seedlings/saplings. Negative PFE values indicated that shrubs had negative effects on seedlings/saplings, which might be observed in scenarios where shrubs are attractive and palatable for herbivores or where shrubs are so dense that seed germination and sapling survival are suppressed due to low light availability within shrubs.

In the fenced sub-plots, there were no sheep or other large herbivores, and the effects of small herbivores were negligible (therefore, we did not consider the effects of small herbivores and focused on grazing effects of large herbivores in this study); thus, the PFE could be attributed to the mediation of abiotic environments by mature shrubs, i.e., microhabitat amelioration (thereafter abbreviated as MA). Therefore, we calculated the MA for each sub-plot using the following formula:

$\mathrm{MA}=\mathrm{PFE}$ in fenced plots

Positive MA values indicated that shrubs had microhabitat amelioration effects on seedlings/saplings. MA values of zero (or indistinguishable from zero) indicated that shrubs had no microhabitat amelioration effect on seedlings/saplings. Negative MA values indicated that presence of shrubs made the microhabitat even more stressful for seedlings/saplings, which might be observed in the systems where shrubs are so dense that they substantially decrease light availability, or where shrubs compete strongly for water resources, thus seed germination and sapling survival are suppressed. 
In the grazed sub-plots, in addition to MA, the PFE could also be attributed to protection of seedlings or saplings against grazing provided by mature shrubs, i.e., protection against herbivory (thereafter abbreviated as PAH). Therefore, we calculated the PAH for each sub-plot using the following formula:

\section{$\mathrm{PAH}=\mathrm{PFE}$ in the grazed plots $-\mathrm{MA}$}

Positive PAH values indicated that shrubs had protection against herbivory effects on seedlings/saplings. PAH values of zero (or indistinguishable from zero) indicated that shrubs had no protection against herbivory effect on seedlings/saplings. Negative PAH values indicated that presence of shrubs increased the probability of being grazed by herbivores for seedlings/saplings, which might be observed in systems where shrubs are attractive and palatable for herbivores.

We also calculated the proportion (\%) of the PFE attributable to MA and PAH by dividing these indices by their associated PFE values as follows:

Proportion of $\mathrm{MA}=\mathrm{MA} / \mathrm{PFE}$

Proportion of $\mathrm{PAH}=\mathrm{PAH} / \mathrm{PFE}$

The calculation processes of PFE, MA, PAH, and proportion of PFE attributable to MA versus PAH are shown in Table 2.

Relative interaction intensity index (RII) (Armas et al. 2004) is usually used when interspecific interactions are investigated, which is an index originally based on biomass of plant individuals and thus is more suitable to compare the natures and intensities of interspecific interactions between plant individuals. In this study, we used PFE to evaluate facilitative effects of shrubs on seedlings/saplings' survival, since it is quantified based on survival number of seedlings/saplings, and it can provide meaningful evaluation (on the basis of survival number of seedlings/saplings in open spaces) of the facilitative effects of shrubs on seedlings/saplings' survival. More importantly, PFE allows the quantification of the MA and $\mathrm{PAH}(\mathrm{PFE}=\mathrm{MA}+\mathrm{PAH})$, as well as the proportion of the PFE attributable to MA and PAH.
We performed ANOVAs to examine the differences in PFE (three-way ANOVAs), MA (two -way ANOVAs), PAH (three-way ANOVAs), and proportions of MA and PAH (three-way ANOVAs) among climate zones, grazing intensities, and growth stages and to evaluate the interactive effects among climate zone, grazing intensity, and growth stage. We used Tukey HSD post hoc tests to examine differences between specific treatments. We performed $t$ tests to compare PFE between the fenced and mildly grazed plots in the intensively arid zone, because there was no seedling or sapling survival in open space in the severely grazed treatment in the intensively arid, so we could not calculate the PFE. We also used $t$ tests to compare PFE between the two growth stages, MA between the two growth stages, PAH between the two grazing intensities, and PAH between the two growth stages. All analyses were performed using SPSS 16.0 (SPSS Inc.).

\section{Results}

\subsection{Plant facilitation efficiency}

The PFE across all four climatic aridity zones, three grazing intensities, and two growth stages (6-month-old seedlings and 18-month-old saplings) were all positive. This indicates that C. stenophylla shrubs have intraspecific facilitative effects on seedling and sapling establishment across its range on the Inner Mongolia Plateau (Fig. 1).

PFE increased as climatic drought stress increased. For example, for 18-month saplings under mild grazing, the PFEs in the semi-arid, arid, very arid, and intensively arid zones were 1.17, 1.90, 3.20, and 5.62, respectively (Fig. 1 and Table 3).

PFE increased as grazing intensity increased. For example, for 18-month saplings in the very arid zone, the PFEs for fenced, mild grazing, and severe grazing treatments were 1.49, 3.20, and 6.70, respectively (Fig. 1 and Table 3).

Table 2 The calculation processes of PFE, MA, PAH, and the proportion of PFE attributable to MA versus PAH

\begin{tabular}{llll}
\hline & Fenced & Mild grazing & Severe grazing \\
\hline Survivals under canopy & 22 & 10 & 5 \\
Survivals in open spaces & 19 & 7 & 3 \\
PFE & $(22-19) / 19=0.158$ & $(10-7) / 7=0.429$ & $(5-3) / 3=0.667$ \\
MA & 0.158 & 0.158 & 0.158 \\
PAH & 0 & $0.429-0.158=0.271$ & $0.667-0.158=0.509$ \\
MA proportion & $(0.158 / 0.158) \times 100 \%=100 \%$ & $(0.158 / 0.429) \times 100 \%=36.8 \%$ & $(0.158 / 0.667) \times 100 \%=23.7 \%$ \\
PAH proportion & $(0 / 0.158) \times 100 \%=0 \%$ & $(0.271 / 0.429) \times 100 \%=63.2 \%$ & $(0.509 / 0.667) \times 100 \%=76.3 \%$ \\
\hline
\end{tabular}




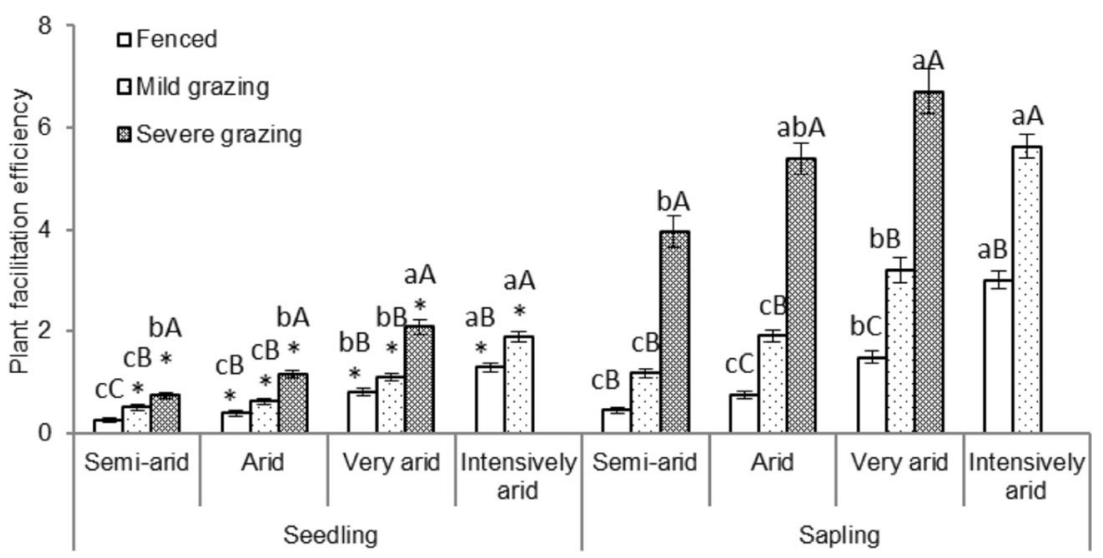

Fig. 1 Plant facilitation efficiency (PFE), which indicates the facilitative effects of mature C. stenophylla shrubs on the survival of intraspecific seedlings and saplings, across the four climatic aridity zones and the three grazing intensities. Data are means $\pm \operatorname{SE}(n=3$ per treatment). For a particular growth stage and grazing intensity, different letters (lowercase) indicate significant differences between climate zones, and

PFE was also higher among older saplings. For example, in the very arid zone with severe grazing, the PFE was 2.08 for seedlings and 6.70 for saplings (Fig. 1 and Table 3). for a particular growth stage and climate zone, different letters (uppercase) indicate significant differences between grazing intensities (Tukey HSD tests or $t$ tests, $P<0.05$ ). For a particular climate zone and grazing intensity, asterisks indicate significant differences between seedling and sapling stages $(t$ tests, $P<0.05)$

The interaction of climatic aridity $\times$ grazing intensity, climatic aridity $\times$ growth stage, grazing intensity $\times$ growth stage, and climatic aridity $\times$ grazing intensity $\times$ growth stage all had
Table 3 Summary of ANOVAs examining the effects of climate zone, grazing intensity, and growth stage, as well as their interactions on PFE, MA, PAH, and the proportion (relative importance) of MA versus PAH

\begin{tabular}{|c|c|c|c|}
\hline Source of variance & $d f$ & $F$ & $P$ \\
\hline \multicolumn{4}{|l|}{ PFE } \\
\hline Climate zone & 3,44 & 190.42 & $<0.01$ \\
\hline Grazing intensity & 2,44 & 416.65 & $<0.01$ \\
\hline Growth stage & 1,44 & 951.33 & $<0.01$ \\
\hline Climate zone $\times$ grazing intensity & 5,44 & 9.49 & $<0.01$ \\
\hline Climate zone $\times$ growth stage & 3,44 & 39.57 & $<0.01$ \\
\hline Grazing intensity $\times$ growth stage & 2,44 & 193.65 & $<0.01$ \\
\hline $\begin{array}{l}\text { Climate zone } \times \text { grazing intensity } \times \\
\text { growth stage }\end{array}$ & 5,44 & 2.75 & 0.03 \\
\hline \multicolumn{4}{|l|}{ MA } \\
\hline Climate zone & 3,16 & 145.23 & $<0.01$ \\
\hline Growth stage & 1,16 & 122.80 & $<0.01$ \\
\hline Climate zone $\times$ growth stage & 3,16 & 26.14 & $<0.01$ \\
\hline \multicolumn{4}{|l|}{ PAH } \\
\hline Climate zone & 3,28 & 27.13 & $<0.01$ \\
\hline Grazing intensity & 1,28 & 326.23 & $<0.01$ \\
\hline Growth stage & 1,28 & 581.10 & $<0.01$ \\
\hline Climate zone $\times$ grazing intensity & 2,28 & 4.14 & 0.027 \\
\hline Climate zone $\times$ growth stage & 3,28 & 8.88 & $<0.01$ \\
\hline Grazing intensity $\times$ growth stage & 1,28 & 159.14 & $<0.01$ \\
\hline $\begin{array}{l}\text { Climate zone } \times \text { grazing intensity } \times \\
\text { growth stage }\end{array}$ & 2,28 & 0.429 & 0.655 \\
\hline \multicolumn{4}{|l|}{ Proportion of MA versus PAH } \\
\hline Climate zone & 3,44 & 15.38 & $<0.01$ \\
\hline Grazing intensity & 2,44 & 1665.24 & $<0.01$ \\
\hline Growth stage & 1,44 & 150.71 & $<0.01$ \\
\hline
\end{tabular}


significant effects on PFE (Table 3). As growth time (age) increased, the positive effects of grazing on PFE increased. Other interactions were rather difficult to interpret (Fig. 1).

\subsection{Microhabitat amelioration and protection against herbivory}

MA increased as climatic drought stress increased. For 6-month seedlings, MA was 0.25 in the semi-arid zone, 0.40 in the arid zone, 0.80 in the very arid zone, and 1.29 in the intensively arid zone (Fig. 2 and Table 3).

MA sharply increased as growth time (age) increased. For 18-month saplings, MA was 0.45 in the semi-arid zone, 0.75 in the arid zone, 1.49 in the very arid zone, and 3.00 in the intensively arid zone; these values for 18-month saplings were about twice as high as those for 6-month seedlings in the same climate zone (Fig. 2 and Table 3).

The interaction of climatic aridity $\times$ growth stage had a significant effect on MA (Table 3). As growth time (age) increased, the positive effect of climatic drought stress on MA increased (Fig. 2).

All protection against herbivory $(\mathrm{PAH})$ values were positive. PAH sharply increased as grazing intensity increased. Six months after sowing, under severe grazing, the PAHs in the semi-arid, arid, and very arid zones were $1.91,3.27$, and 4.23 times higher than those under mild grazing, respectively (Fig. 3 and Table 3). PAH also sharply increased as growth time (age) increased. PAH for 18-month saplings was consistently three to seven times higher than that for 6-month seedlings (Fig. 3 and Table 3).

PAH increased as climatic drought stress increased. For 18-month saplings under mild grazing, PAH was 0.72 in the semi-arid zone, 1.15 in the arid zone, 1.71 in the very arid zone, and 2.62 in the intensively arid zone; under severe grazing, PAH was 3.50 in the semiarid zone, 4.63 in the arid zone, and 5.21 in the very arid zone (Fig. 3 and Table 3).

The interaction of climatic aridity $\times$ grazing intensity, climatic aridity $\times$ growth stage, and grazing intensity $\times$ growth stage had all significant effects on PAH (Table 3 ). These interactions were rather difficult to interpret (Fig. 3).

\subsection{Relative importance of microhabitat amelioration versus protection against herbivory}

The proportion of the PFE attributable to MA increased as climatic drought stress increased. For example, for the 18-month saplings under mild grazing, MA proportions were $38.0 \%$ in the semi-arid zone, $39.3 \%$ in the arid zone, $46.6 \%$ in the very arid zone, and $53.4 \%$ in the intensively arid zone. The PAH proportion increased as grazing intensity increased and was higher for later (older) growth stages. For example, among 6-month seedlings, the PAH proportions were about $30-50 \%$ in mild grazing treatments and about $60-70 \%$ in severe grazing treatments, whereas among 18-month saplings, the $\mathrm{PAH}$ proportion were about $50-60 \%$ in mild grazing treatments and about $80-90 \%$ in severe grazing treatments (Tables 3 and 4).

\section{Discussion}

\subsection{Positive feedback in shrub recruitment}

There were consistent positive effects of pre-existing C. stenophylla shrubs on intraspecific seedling and sapling

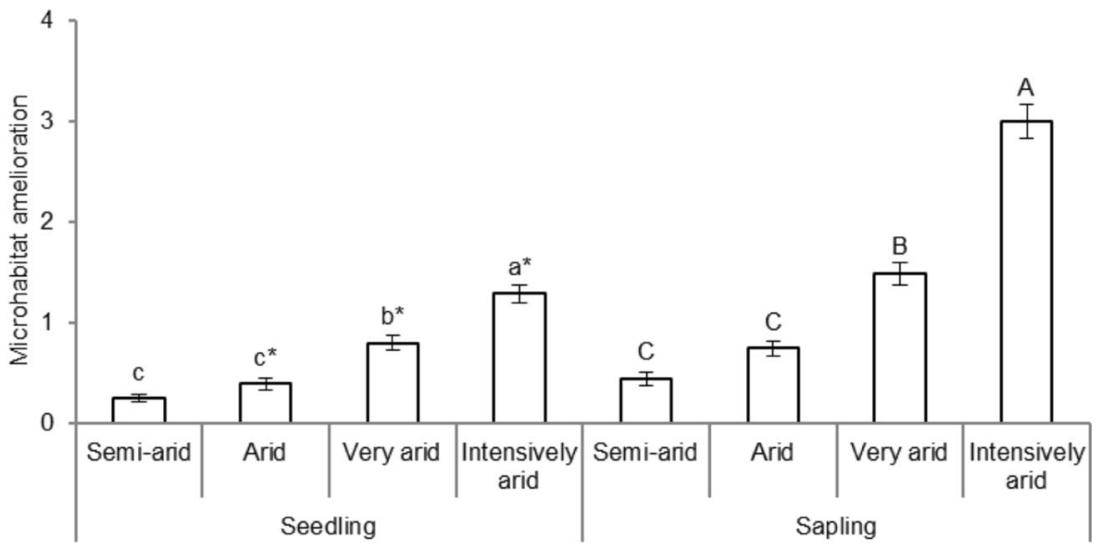

Fig. 2 Microhabitat amelioration (MA), which quantifies one component of the facilitative effects of $C$. stenophylla shrubs on the survival of intraspecific seedlings and saplings, across the four climatic aridity zones. Data presented here are only based on the fenced plots. Data are means $\pm \operatorname{SE}$ ( $n=3$ per treatment). For a particular growth stage, different letters (lowercase for seedling stage, uppercase for sapling stage) indicate significant differences between climate zones (Tukey HSD tests, $P<0.05$ ). For a particular climate zone, asterisks indicate significant differences between seedling and sapling stages $(t$ tests, $P<0.05)$ 


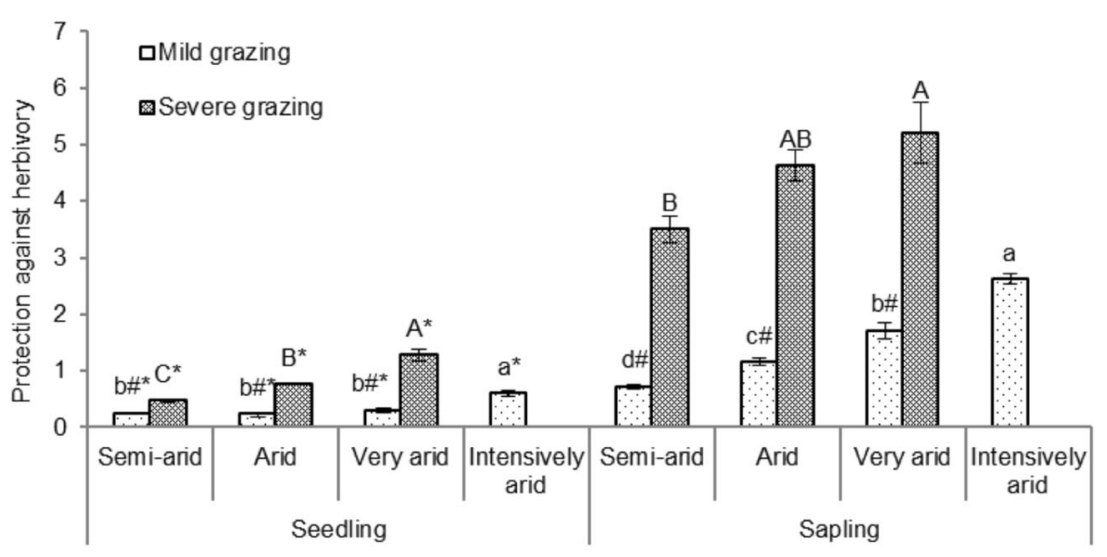

Fig. 3 Protection against herbivory (PAH), which quantifies one component of the facilitative effect of $C$. stenophylla shrubs on the survival of seedlings and saplings, across the four climatic aridity zones and the three grazing intensities treatments. Data are means $\pm \operatorname{SE}(n=3$ per treatment). For a particular growth stage and grazing intensity, different letters (lowercase for mild grazing, uppercase for severe

establishment in all four climatic zones, all three grazing intensities, and for both growth stages, which were consistent with previous studies on other shrub species (Gómez-Aparicio et al. 2004; Tíscar and Linares 2014; Ameztegui and Coll 2015; Holmgren et al. 2015). These results demonstrated that established shrubs would promote new juvenile recruitment and population expansion, which suggested that shrub establishment has a positive feedback effect.

\subsection{Mechanisms of facilitation-microhabitat amelioration and protection against herbivory}

Our results showed that mature shrubs facilitated seedling and sapling establishment via both MA and PAH, which supported the prediction of Bertness and Callaway (1994). In treatment plots protected from grazing, shrubs would have only provided a MA, whereas, in grazed treatments, shrubs would have provided facilitative effects to seedlings and saplings through both MA and PAH. grazing) indicate significant differences between climate zones (Tukey HSD tests, $P<0.05$ ). For a particular growth stage and climate zone, number signs indicate significant differences between the two grazing intensities, and for a particular climate zone and grazing intensity, asterisks indicate significant differences between seedling and sapling stages $(t$ tests, $P<0.05)$

MA operates mechanistically when shrubs ameliorate stressful abiotic conditions (Bertness and Callaway 1994) by creating favorable localized environmental conditions within the protection of the mature C. stenophylla (e.g., lower wind speed, higher humidity, less temperature fluctuation, higher soil moisture, higher soil fertility, etc.) (Zhao et al. 2007; Dong et al. 2009; Guan et al. 2016; Liu et al. 2016), which then enhance seed germination and/or survival of seedlings/ saplings of $C$. stenophylla. Besides, for intraspecific sapling establishment, MA of mature shrubs may also involve parental effect or kin selection.

MA provided by mature C. stenophylla shrubs increased as climatic drought stress increased. This was probably because, as drought stress increased, micro-environmental conditions under shrub canopies became relatively more favorable and thus more important to seedling and sapling establishment. Since environmental conditions are relatively benign in the semi-arid zone (Table 1), C. stenophylla saplings are more able to become established both under shrub canopies and in open spaces. Furthermore, in the semi-arid zone,

Table 4 Proportion (\%) of facilitative effects attributable to microhabitat amelioration (MA) versus protection against herbivory (PAH) across the four climatic aridity zones, three grazing intensities, and two growth stages

\begin{tabular}{|c|c|c|c|c|c|c|c|c|c|}
\hline & & \multicolumn{2}{|l|}{ Semi-arid } & \multicolumn{2}{|l|}{ Arid } & \multicolumn{2}{|l|}{ Very arid } & \multicolumn{2}{|c|}{ Intensively arid } \\
\hline & & MA & PAH & MA & PAH & MA & PAH & MA & PAH \\
\hline \multirow[t]{3}{*}{ Seedling } & Fenced & $100 \pm 0$ & $0 \pm 0$ & $100 \pm 0$ & $0 \pm 0$ & $100 \pm 0$ & $0 \pm 0$ & $100 \pm 0$ & $0 \pm 0$ \\
\hline & Mild grazing & $49.6 \pm 3.5$ & $50.4 \pm 3.5$ & $62.9 \pm 6.0$ & $37.1 \pm 6.0$ & $72.3 \pm 3.8$ & $27.7 \pm 3.8$ & $68.4 \pm 2.0$ & $31.6 \pm 2.0$ \\
\hline & Severe grazing & $34.0 \pm 3.4$ & $66.0 \pm 3.4$ & $34.1 \pm 3.4$ & $65.9 \pm 3.4$ & $38.5 \pm 2.2$ & $61.5 \pm 2.2$ & - & - \\
\hline \multirow[t]{3}{*}{ Sapling } & Fenced & $100 \pm 0$ & $0 \pm 0$ & $100 \pm 0$ & $0 \pm 0$ & $100 \pm 0$ & $0 \pm 0$ & $100 \pm 0$ & $0 \pm 0$ \\
\hline & Mild grazing & $38.0 \pm 3.4$ & $62.0 \pm 3.4$ & $39.3 \pm 2.2$ & $60.7 \pm 2.2$ & $46.6 \pm 0.46$ & $53.4 \pm 0.46$ & $53.4 \pm 1.2$ & $46.6 \pm 1.2$ \\
\hline & Severe grazing & $11.3 \pm 0.9$ & $88.7 \pm 0.9$ & $13.9 \pm 1.1$ & $86.1 \pm 1.1$ & $22.6 \pm 3.0$ & $77.4 \pm 3.0$ & - & - \\
\hline
\end{tabular}

Data are means $\pm \operatorname{SE}(n=3$ per treatment $)$ 
C. stenophylla shrubs were smaller in canopy size (Ma et al. 2013), which suggests relatively smaller differences in microenvironmental conditions within shrub canopies compared to in open space. As a result, MA by mature shrubs should be less important to seedling/sapling establishment in the semiarid zone. However, as climatic drought stress increases from the semi-arid zone to the intensively arid zone, environmental conditions and resource availability become increasingly stressful and limiting of sapling establishment. Moreover, C. stenophylla shrubs become increasingly larger in canopy size along the same climatic gradient from the semi-arid zone to the intensively arid zone (Ma et al. 2013). Therefore, not only do the differences in conditions within canopies vs. in open space become increasingly greater as climatic drought stress increases but also the conditions in open space become increasingly stressful for shrub germination and establishment. In the intensively arid zone, microhabitat amelioration by mature shrubs became a necessary condition for sapling establishment of $C$. stenophylla, in that the presence of a protective shrub canopy could increase seedling and sapling survival rates by 2.3 times (for seedlings in fenced plot) to 4 times (saplings in fenced plot).

MA provided by mature $C$. stenophylla shrubs was also greater for older life stages. MA in the second growing season (in 2014) was about twice as high as that in the first growing season (in 2013), which suggests that MA could be considered to accumulate over time (as cohorts continue to age and individuals die) for at least the first 2 years of growth. In the first growing season, microclimate amelioration by mature shrubs played a major role in promoting seed germination and seedling survival, whereas, in the second growing season, the "resource island" (Zhao et al. 2007; Dong et al. 2009; Guan et al. 2016; Liu et al. 2016) mechanism of C. stenophylla shrub may have played a stronger role in enhancing sapling survival.

Protection of shrub seedlings against herbivory provided by mature shrubs often occurs in areas with relatively high herbivore pressure and with shrub species with spinose or unpalatable canopies (Bertness and Callaway 1994; Callaway et al. 2005; Graff et al. 2007). The PAH provided by mature $C$. stenophylla shrubs was mainly due to its spinose and compact cushion-like canopies.

PAH provided by mature $C$. stenophylla increased as grazing intensity increased. This is most likely due to the increased probability that seedlings or saplings would be grazed in open spaces as the overall grazing intensity increased. Thus, the protective effect of shrub canopies on seedling and saplings against herbivory became more significant.

Importantly, as climatic drought stress increased from the semi-arid zone to the intensively arid zone, the PAH of C. stenophylla also increased. Our previous studies have shown that canopies area and height of $C$. stenophylla generally increase from the semi-arid zone to the intensively arid zone (Ma et al. 2013), and greater canopy size is expected to provide better PAH for seedlings and saplings.

PAH of C. stenophylla also increased as seedlings/saplings growth time (age) increased. PAHs among saplings were about three to seven times higher than the PAHs among seedlings. As with MA, this suggests that PAH could be considered to accumulate over time. In the first growing season, the growth stages included seed germination (about 2 months, Apr to May) and seedling growth (about 4 months, Jun to Sept). Earlier seedling stages (younger seedlings) and smaller seedling $(2-10 \mathrm{~cm})$ should decrease the probability of a seedling being consumed by a large herbivore. In the second growing season, sapling growing time was longer (about 6 months, Apr to Sept) and saplings were larger $(10-15 \mathrm{~cm})$, which should increase the likelihood that all or part of these saplings would be consumed by large herbivores. Therefore, protection against herbivory provided by mature $C$. stenophylla was relatively more important in the second growing season than in the first one.

\subsection{Relative importance of microhabitat amelioration and protection against herbivory}

The relative importance of MA and PAH varied across our experimental abiotic gradient, grazing gradient, and growth stages. Increases in the relative importance of MA (MA proportion) were associated with increases in climatic drought stress, which suggests, logically, that the role played by shrubs in providing microenvironment amelioration becomes more important to seedling and sapling establishment as climatic drought stress becomes more severe (largely because it becomes more difficult for seeds to germinate and for saplings to survive in open spaces). Increases in the relative importance of PAH (PAH proportion) were associated with increases in grazing intensity, which suggests, logically, that the role played by shrubs in safeguarding seedlings and saplings from herbivory becomes more important as the severity of local grazing pressure increases (largely because sapling survival decreases rapidly in open spaces as grazing intensity increases). The relative importance of PAH was also higher among later growth stages (older saplings), which reflects the fact that the probability of grazing was higher for larger seedlings/saplings and suggests that the protection provided by shrubs was more important to the survival of saplings than seedlings.

\subsection{Variation of plant facilitation efficiency}

Studies showed that the importance of shrub facilitation of woody seedling survival increased as abiotic stress increased (Hastwell and Facelli 2003; Gómez-Aparicio 2009; Petrou and Milios 2012). However, a study by Jankju (2013) in arid rangelands suggested potentially greater complexity, 
suggesting that shrubs could facilitate the seedling establishment of understory herb species in moderate drought stress conditions, but that these positive effects were suppressed and outweighed by competition under severe drought conditions. Our results showed that the facilitation of mature C. stenophylla shrubs on intraspecific sapling survival increased as climatic aridity increased and that this pattern was maintained even in extremely arid conditions, which is consistent with the stress gradient hypothesis (Bertness and Callaway 1994; Maestre et al. 2009). This is attributable to increases in MA and PAH as climatic drought stress increases. Several expected outcomes of an increase in the importance of shrub facilitation as abiotic stress increases are reflected in the results of prior studies, which have shown that overall C. stenophylla population aggregation (Xie et al. 2015) and shrub canopy size (Ma et al. 2013) both increase as climatic aridity increases. Our results suggested that plant facilitation effects would influence not only species distributions within communities (Bertness and Callaway 1994) but also plant distributions within populations (population spatial patterns).

Smit et al. (2007) found that under higher grazing pressures, facilitative species became less protective. However, our results showed the opposite; as grazing intensity increased, the facilitative effects of $C$. stenophylla on its own seedlings and saplings gradually increased, which is consistent with the speculation of Bertness and Callaway (1994). This is at least partially attributable to the sharp increases in PAH observed as grazing intensity increased (Fig. 3). Protection seedlings and saplings against herbivory by established shrubs have promoted shrub population recruitment. Meanwhile, grazing on the Inner Mongolia Plateau has led to relative increases in shrub recruitment in association with established shrubs, which has promoted the development of an aggregated distribution of $C$. stenophylla individuals (Xie et al. 2015) and canopy size increase (Ma et al. 2013). Our results suggested that facilitation effects of mature shrubs on seedling and sapling establishment might result in an increase in aggregated distribution of shrubs as grazing intensity increased.

The facilitative effects of mature C. stenophylla shrubs on its seedlings/saplings also gradually increased as seedling/ sapling growth time increased (Fig. 1), which was due to the increase of MA and PAH as seedling/sapling growth time increase (Figs. 2 and 3). Our results suggested that facilitation effects of mature shrubs on recruitment of woody plants exist in seedling and sapling stages.

\section{Conclusions}

Based on our results, we can draw several conclusions: (1) Caragana shrubs have intraspecific facilitative effects on seedling and sapling establishment. Therefore, Caragana shrub establishment has a positive feedback effect. (2) Facilitation of seedling and sapling establishment by mature shrubs involves both MA and PAH mechanisms. MA increased as climatic drought stress and seedling/sapling growth time increased. PAH increased as climatic drought stress, grazing intensity, and seedling/sapling growth time increased. (3) Increases in both MA and PAH as climatic drought stress increased resulted in overall increases in PFE as climatic drought stress increased. Increases in PAH as grazing intensity increased also resulted in overall increases in PFE as grazing intensity increased. As growth time of seedlings and saplings increased, PFE, MA, and PAH all increased. (4) The importance of shrub's MA increased as climatic drought stress increased. In contrast, the importance of shrub's PAH increased as both grazing intensity and the growth time of seedlings and saplings increased. (5) Pre-existing shrubs have organism island effects in grassland ecosystems.

Acknowledgements We thank Xilinhaote Grassland Management office, Siziwang Grassland Management office, Etuoke Grassland Management office, and Alashanzuo Grassland Management office for the logistical supports to this study.

Author contribution Cheng-Cang Ma designed the experiment; Li-Na Xie, Zhe Liu, and Wei-Zhong Chen did the experiment; Li-Na Xie, Cheng-Cang Ma, and Christopher A. Gabler wrote the paper; Li-Na Xie and Hong-Yu Guo analyzed the data; Cheng-Cang Ma and Song $\mathrm{Gu}$ supervised the work; and Cheng-Cang Ma coordinated the research project.

Funding This study was supported by National Natural Science Foundation of China [31570453, 31170381].

\section{References}

Aerts R, November E, Borght I, Behailu M, Hermy M, Muys B (2006) Effects of pioneer shrubs on the recruitment of the fleshy-fruited tree Olea europaea ssp. cuspidata in Afromontane savanna. Appl Veg Sci 9:117-126

Aerts R, Negussie A, Maes W, November E, Hermy M, Muys B (2007) Restoration of dry Afromontane Forest using pioneer shrubs as nurse-plants for Olea europaea ssp. cuspidata. Restor Ecol 15: $129-138$

Ameztegui A, Coll L (2015) Herbivory and seedling establishment in Pyrenean forests: influence of micro- and meso-habitat factors on browsing pressure. Forest Ecol Manag 342:103-111

Armas C, Ordiales R, Pugnaire FI (2004) Measuring plant interactions: a new comparative index. Ecology 85:2682-2686

Bertness MD, Callaway R (1994) Positive interactions in communities. Trends Ecol Evol 9:191-193

Boulant N, Navas ML, Corcket E, Lepart J (2008) Habitat amelioration and associational defence as main facilitative mechanisms in Mediterranean grasslands grazed by domestic livestock. Ecoscience 15:407-415

Boulant N, Garnier A, Curt T, Lepart J (2009) Disentangling the effects of land use, shrub cover and climate on the invasion speed of native and introduced pines in grasslands. Divers Distrib 15:1047-1059

Brooker RW, Maestre FT, Callaway RM, Lortie CL, Cavieres LA, Georges K, Liancourt P, Katja T, Travis JMJ, Anthelme F, Armas C, Coll L, Corcket E, Delzon S, Forey E, Kikvidze Z, Olofsson J, 
Pugnaire F, Quiroz CL, Saccone P, Schiffers K, Seifan M, Touzard B (2008) Facilitation in plant communities: the past, the present, and the future. J Ecol 96:18-34

Caldeira MC, Ibanez I, Nogueira C, Bugalho MN, Lecomte X, Moreira A, Pereira JS (2014) Direct and indirect effects of tree canopy facilitation in the recruitment of Mediterranean oaks. J Appl Ecol 51: 349-358

Callaway RM, Brooker RW, Choler P, Kikvidze Z, Lortie CJ, Michalet R, Paolini L, Pugnaire FI, Newingham B, Aschehoug ET (2002) Positive interactions among alpine plants increase with stress. Nature 417:844-848

Callaway RM, Kikodze D, Chiboshvili M, Khetsuriani L (2005) Unpalatable plants protect neighbors from grazing and increase plant community diversity. Ecology 86:1856-1862

Castro J, Zamora R, Hódar JA, Gómez JM, Gómez-Aparicio L (2004) Benefits of using shrubs as nurse plants for reforestation in Mediterranean mountains: a 4-year study. Restor Ecol 12:352-358

Cavieres LA, Badano EI, Sierra-Almeida A, Gómez-González S, MolinaMontenegro MA (2006) Positive interactions between alpine plant species and the nurse cushion plant Laretia acaulis do not increase with elevation in the Andes of central Chile. New Phytol 169:59-69

Chambers JC (2001) Pinus monophylla establishment in an expanding Pinus-Juniperus woodland: environmental conditions, facilitation and interacting factors. J Veg Sci 12:27-40

Choler P, Michalet R, Callaway RM (2001) Facilitation and competition on gradients in alpine plant communities. Ecology 82:3295-3308

Dong X, Zhang X, Bao X, Wang J (2009) Spatial distribution of soil nutrients after the establishment of sand-fixing shrubs on sand dune. Plant Soil Environ 55:288-294

Gómez-Aparicio L (2009) The role of plant interactions in the restoration of degraded ecosystems: a meta-analysis across life-forms and ecosystems. J Ecol 97:1202-1214

Gómez-Aparicio L, Zamora R, Gómez JM, Hódar JA, Castro J, Baraza E (2004) Applying plant facilitation to forest restoration: a metaanalysis of the use of shrubs as nurse plants. Ecol Appl 14:11281138

Gómez-Aparicio L, Gómez JM, Zamora R, Boettinger JL (2005a) Canopy vs. soil effects of shrubs facilitating tree seedlings in Mediterranean montane ecosystems. J Veg Sci 16:191-198

Gómez-Aparicio L, Valladares F, Zamora R, Luis Quero J (2005b) Response of tree seedlings to the abiotic heterogeneity generated by nurse shrubs: an experimental approach at different scales. Ecography 28:757-768

Gómez-Aparicio L, Zamora R, Castro J, Hódar JA (2008) Facilitation of tree saplings by nurse plants: microhabitat amelioration or protection against herbivores? J Veg Sci 19:161-172

Graff P, Aguiar MR, Chaneton EJ (2007) Shifts in positive and negative plant interactions along a grazing intensity gradient. Ecology 88: $188-199$

Grau O, Rautio P, Heikkinen J, Saravesi K, Kozlov MV, Markkola A (2010) An ericoid shrub plays a dual role in recruiting both pines and their fungal symbionts along primary succession gradients. Oikos 119:1727-1734

Guan LJ, Mei XF, Zhang YY, Han L, Li QF, Ma CC (2016) The temporal and spatial distribution of soil water and nutrient of Caragana stenophylla Nabkha in the different habitats of the Inner Mongolia Plateau. Arid Zone Res 33:253-259

Gutiérrez JR, Holmgren M, Manrique R, Squeo FA (2007) Reduced herbivore pressure under rainy ENSO conditions could facilitate dryland reforestation. J Arid Environ 68:322-330

Harmer R, Kiewitt A, Morgan G, Gill R (2010) Does the development of bramble (Rubus fruticosus L. agg.) facilitate the growth and establishment of tree seedlings in woodlands by reducing deer browsing damage? Forestry 83: 93-102
Hastwell GT, Facelli JM (2003) Differing effects of shade-induced facilitation on growth and survival during the establishment of a chenopod shrub. J Ecol 91:941-950

He Q, Bertness MD, Altieri AH (2013) Global shifts towards positive species interactions with increasing environmental stress. Ecol Lett 16:695-706

Holl KD (2002) Effect of shrubs on tree seedling establishment in an abandoned tropical pasture. J Ecol 90:179-187

Holmgren M, Gómez-Aparicio L, Quero JL, Valladares F (2012) Nonlinear effects of drought under shade: reconciling physiological and ecological models in plant communities. Oecologia 169:293-305

Holmgren M, Lin CY, Murillo JE, Nieuwenhuis A, Penninkhof J, Sanders N, Bart T, Veen H, Vasander H, Vollebregt ME (2015) Positive shrub-tree interactions facilitate woody encroachment in boreal peatlands. J Ecol 103:58-66

Jankju M (2013) Role of nurse shrubs in restoration of an arid rangeland: effects of microclimate on grass establishment. J Arid Environ 89: 103-109

Legras EC, Vander Wall SB, Board DI (2010) The role of germination microsite in the establishment of sugar pine and Jeffrey pine seedlings. Forest Ecol Manag 260:806-813

Liu Z, Mei XF, Zhang W, Ma CC, Li QF (2016) The microclimate characteristics of Caragana stenophylla shrub canopy in desert region. Arid Zone Res 33:308-312

López RP, Valdivia S, Sanjinés N, De la Quintana D (2007) The role of nurse plants in the establishment of shrub seedlings in the semi-arid subtropical Andes. Oecologia 152:779-790

Ma CC, Zhang JH, Guo HY, Li QF, Xie LN, Gao YB (2013) Alterations in canopy size and reproduction of Caragana stenophylla along a climate gradient on the Inner Mongolian Plateau. Flora 208:97-103

Maestre FT, Valladares F, Reynolds JF (2005) Is the change of plant-plant interactions with abiotic stress predictable? A meta-analysis of field results in arid environments. J Ecol 93:748-757

Maestre FT, Callaway RM, Valladares F, Lortie CJ (2009) Refining the stress-gradient hypothesis for competition and facilitation in plant communities. J Ecol 97:199-205

Maher KA, Hobbs RJ, Yates CJ (2010) Woody shrubs and herbivory influence tree encroachment in the sandplain heathlands of southwestern Australia. J Appl Ecol 47:441-450

Martínez ML (2003) Facilitation of seedling establishment by an endemic shrub in tropical coastal sand dunes. Plant Ecol 168:333-345

Meng M, Zhi Z (2004) Aridity index and its applications in geoecological study. Acta Phytoecologica Sin 28:853-861

Otto R, Krüsi BO, Delgado JD, Fernández-Palacios JM, García-Del-Rey E, Arévalo JR (2010) Regeneration niche of the Canarian juniper: the role of adults, shrubs and environmental conditions. Ann Forest Sci 67:709

Petrou P, Milios E (2012) Establishment and survival of Pinus brutia Ten. seedlings over the first growing season in abandoned fields in central Cyprus. Plant Biosyst 146:522-533

Pugnaire FI, Luque MT (2001) Changes in plant interactions along a gradient of environmental stress. Oikos 93:42-49

Smit C, Vandenberghe C, Den Ouden J, Müller-Schärer H (2007) Nurse plants, tree saplings and grazing pressure: changes in facilitation along a biotic environmental gradient. Oecologia 152:265-273

Smit C, Ouden J, Díaz M (2008) Facilitation of Quercus ilex recruitment by shrubs in Mediterranean open woodlands. J Veg Sci 19:193-200

Tálamo A, Barchuk A, Cardozo S, Trucco C, MarÁs G, Trigo C (2015a) Direct versus indirect facilitation (herbivore mediated) among woody plants in a semiarid Chaco forest: a spatial association approach. Austral Ecol 40:573-580

Tálamo A, Barchuk AH, Garibaldi LA, Trucco CE, Cardozo S, Mohr F (2015b) Disentangling the effects of shrubs and herbivores on tree regeneration in a dry Chaco forest (Argentina). Oecologia 178:847854 
Tielbörger K, Kadmon R (2000) Temporal environmental variation tips the balance between facilitation and interference in desert plants. Ecology 81:1544-1553

Tíscar PA, Linares JC (2014) Large-scale regeneration patterns of Pinus nigra subsp. salzmannii: poor evidence of increasing facilitation across a drought gradient. Forests 5:1-20

Torres RC, Renison D (2015) Effects of vegetation and herbivores on regeneration of two tree species in a seasonally dry forest. J Arid Environ 121:59-66
Williams K, Westrick LJ, Williams B (2006) Effects of blackberry (Rubus discolor) invasion on oak population dynamics in a California savanna. Forest Ecol Manag 228:187-196

Xie LN, Guo HY, Gabler CA, Li QF, Ma CC (2015) Changes in spatial patterns of Caragana stenophylla along a climatic drought gradient on the Inner Mongolian Plateau. PLoS One 10:e0121234

Zhao HL, Zhou RL, YZ S, Zhang H, Zhao LY, Drake S (2007) Shrub facilitation of desert land restoration in the Horqin Sand Land of Inner Mongolia. Ecol Eng 31:1-8 